\title{
ISOLATION AND IDENTIFICATION OF CANINE ADENOVIRUS TYPE 2 FROM THE EGYPTIAN DOGS
}

\author{
Kasem, S. G, ${ }^{1}$ Kotb, A. M, ${ }^{2}$ Hafez, Y. $M^{3}$ and Al-Maria, N. $F^{3}$ \\ ${ }^{1,4}$ Dept. of Virology, Fac. of Vet. Medicine, Kafrelsheikh Univ. \\ ${ }^{2}$ Veterinary Serum and Vaccine Research Institute. Abbassia, Cairo, Egypt \\ ${ }^{3}$ Dept. of Agric. Botany, EPCRS Excellence Center, Fac. of Agric. Kafrelsheikh Univ.
}

\begin{abstract}
Canine infectious tracheobronchitis (kennel cough) caused by CAV-2 is one of the most prevalent respiratory infections of dogs. Kennel cough characterized by frequent dry and hacking coughing high morbidity but low mortality rate. In this study, nasal and ocular discharge samples have been taken from 59 dogs from the veterinary clinics of pet animals in Cairo, Egypt of different age and sex from 2013 to 2014. It showed clinical symptoms, a systemic disease which characterized by fever, diarrhea, vomiting, oculonasal discharge, conjunctivitis, severe moist cough, signs of pulmonary disease and dehydration. Isolated virus was identified by qualitative chromatographic immunoassay by using Anigen Rapid CIRD-3 Ag Test Kit, the result was positive for CAV in only 7 samples. Then the virus from positive samples was passaged for 3 blind passages in Vero cell then subjected to FAT and haemagglutination tests, the results indicated that the virus was most likely to be present in the respiratory tract. The virus was processed and inoculated onto confluent monolayers of MDCK, Vero, BHK21, and MDBK cells for 10 passages using standard virological techniques. The Cytopathic effect (CPE) appeared and MDCK cells were the most susceptible cell culture where they gave the highest infectivity titre.
\end{abstract}

Keywords: Canine Adenovirus, MDCK, Vero, MDBK, BHK21, CPE, kennel cough, FAT. 


\section{INTRODUCTION}

Adenoviruses are viral pathogens isolated from humans as well as farm and domestic animals (Wieliczko et al 2003, Wiśniewski 2004, Koncicki et al 2006, Buonavoglia and Martella 2007, Lynch et al 2011, Truszczyński and Pejsak 2012). Canine adenoviruses (CAVs) belong to the Adenoviridae family, the Mastadenovirus genus. They are nonenveloped viruses sized 70-90 nm, whose genome, in the form of a double DNA strand, is built of 36-44 kilo base pairs (Appel and Binn 1987).

Currently, two antigen types of adenoviruses isolated from dogs are recognized: CAV-1, inducing infectious canine hepatitis (Rubarth's disease), and $\mathrm{CAV}-2$, an etiological factor of canine tracheobronchitis (kennel cough) (Chaturved et al 2008). CAV-2 demonstrates an affinity to the epithelia of upper airways, mostly of the nose, throat, larynx and trachea (Appel et al 1970). It can also contribute to intestinal inflammations (Hamelin et al 1985, Macartney et al 1988). Its presence was revealed in the brain of dogs exhibiting neurological symptoms (Benetka et al 2006). The virus was isolated for the first time in 1961 in Canada from dogs with symptoms of laryngitis and tracheitis (Ditchfield et al 1962). The discovered strain was named Toronto $A 26 / 61$ and it was initially regarded as a variety of CAV-1. However, further studies showed structural and antigen differences between these viral isolates and as a result Toronto A26/61 was recognized as a separate strain and named CAV-2 (Yamamoto and Marusyk 1968, Fairchild and Cohen 1969, Swango et al 1969, Marusyk et al 1970, Marusyk 1972 and Hamelin et al 1984). 
The aim of the present study is to isolate and identify a local strain of CAV in Egypt for early diagnosis of the virus as it resembles many infectious respiratory viruses (canine distemper and canine parainfluenza) by using serological and cell culture techniques for preparing a local vaccine from the local isolate. In further studies, control of this disease will be tested.

\section{MATERIAL AND METHODS}

\subsection{Sampling:}

59 nasal and ocular discharges swab samples were collected from dogs of different age and sex showing illness including off food, rough hair, ocular and nasal discharge, rise in body temperature, cough and rapid respiration rales. They were collected from pet animals clinics in Cairo, Egypt.

\subsection{Qualitative chromatographic immunoassay:}

By using Anigen Rapid CIRD-3 Ag Test Kit. Bionote kit Doc. No.: I 11091E. The principle of it is qualitative detection of canine infectious respiratory disease antigens such as: Canine Distemper virus, Canine Adenovirus (Infectious Canine Hepatitis) and Canine Influenza virus in conjunctiva and nasal discharge.

\subsection{Virus isolation and identification:}

In all cell cultures, the inoculated plates were examined daily by microscopically examination for recording cytopathic effects (CPE). The virus underwent 10 passages in cells, until cytopathogenic effects (CPE) were observed. 
The prepared nasal and ocular discharges samples were inoculated in Vero cell culture and subjected to different serological tests including fluorescent antibody, and haemagglutination techniques.

\subsubsection{Direct fluorescent antibody technique (FAT):}

Direct FAT was applied on infected cell cultures according to $\boldsymbol{H u}$ R.L. el al (2001), Greene (2012) and Bulut et al (2013). Using CAV-2 antiserum conjugated with fluorescein isothiocynate which kindly supplied from department of pet animals vaccines (DOPAV), veterinary serum and vaccine research institute (VSVRI), Abbassia, Cairo, Egypt.

\subsubsection{Haemagglutination (HA) test:}

HA was carried out using human type $\mathrm{O}$ red blood corpuscles according to Parthiban et al (2009).

\subsection{Cell cultures:}

Baby Hamster Kidney (BHK21), African green monkey kidney (Vero), Madin Darby Bovine Kidney (MDBK) and Madin Darby Canine Kidney (MDCK) cell lines were used for virus isolation and propagation according to Yamamoto (1966) and Bulut et al (2013).

All types of cell culture were obtained from (VSVRI), Cairo, Egypt. It was grown in minimal essential media supplemented with $10 \%$ new born calf serum, penicillin at concentration of $100 \mathrm{Iu} / \mathrm{ml}$ and streptomycin at a concentration of $100 \mathrm{ug} / \mathrm{ml}$; the cells were incubated at $37^{\circ} \mathrm{c}$. 
Isolation And Identification Of Canine Adenovirus ...

In all cell cultures, the inoculated plates were examined daily by microscopically examination for recording cytopathic effects (CPE). The virus underwent 10 passages in cells, until cytopathogenic effects (CPE) were observed.

\section{RESULTS AND DISCUSSION}

For detection of virus by Anigen Rapid CIRD-3 Ag Test Kit (Bionote kit) as qualitative chromatographic immunoassay. It concluded the virus was CAV in seven samples from 59 ones as shown in figure 1.

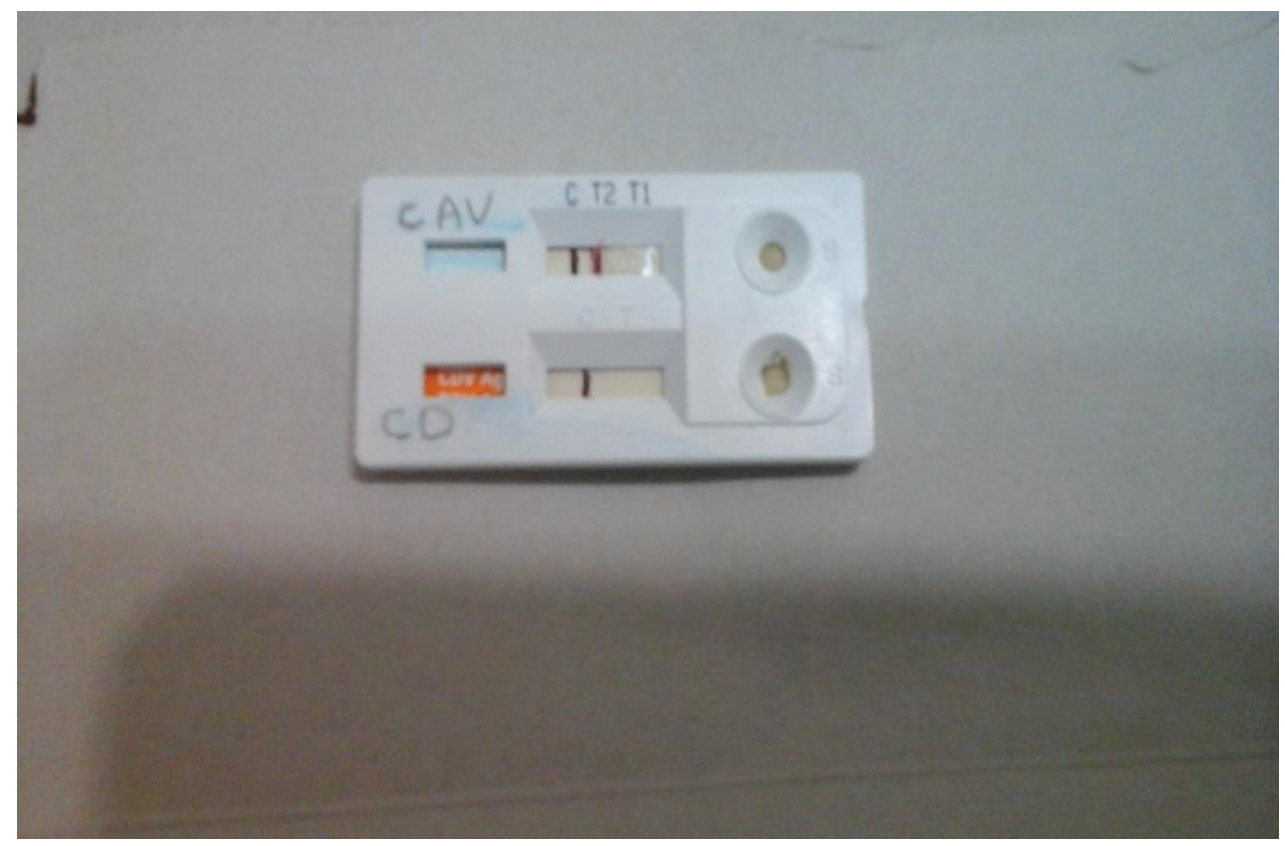

Fig. (1): qualitative chromatographic immunoassay by using Anigen Rapid CIRD-3 Ag Test Kit, $\mathrm{C}=$ control, $\mathrm{T}=$ canine distemper virus test, $\mathrm{T} 1=$ canine Influenza virus test, $\mathrm{T} 2=$ canine Adenovirus test. 
CAV was monitored in nasal-ocular discharge of infected dogs which inoculated in cell culture using FA and HA techniques (Table 1 and Fig. 2), the results were strong positive for FAT showed greenish fluorescence granules in the cytoplasm of infected cells, at the same time there was no fluorescent staining in the control non infected cells and haemagglutination had been occurred strong positively with human blood group "O", where results indicated that the virus was most likely to be adenovirus. These results previously recorded by $\boldsymbol{H u} \boldsymbol{R} . \boldsymbol{L}$. $\boldsymbol{e l}$ al (2001), Greene (2012) and Bulut et al (2013).

Table (1): Monitoring of CAV in nasal and ocular discharges of naturally infected dogs.

\begin{tabular}{|c|c|c|c|}
\hline \multirow{2}{*}{ Tested sample } & \multirow{2}{*}{ Number of sample } & \multicolumn{2}{|c|}{ Used test } \\
\hline & & Mean FAT & Mean HA titre \\
\hline Nasal discharge & 7 & +++ & $64(+++)$ \\
\hline Ocular discharge & 7 & ++ & + \\
\hline
\end{tabular}

FAT $=$ direct fluorescent antibody technique.

$\mathrm{HA}=$ haemagglutination using human RBCs type " $\mathrm{O}$ "

$+=$ weak positive.$++=$ moderate positive.$+++=$ strong positive.

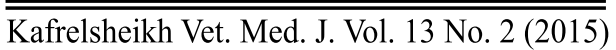


A

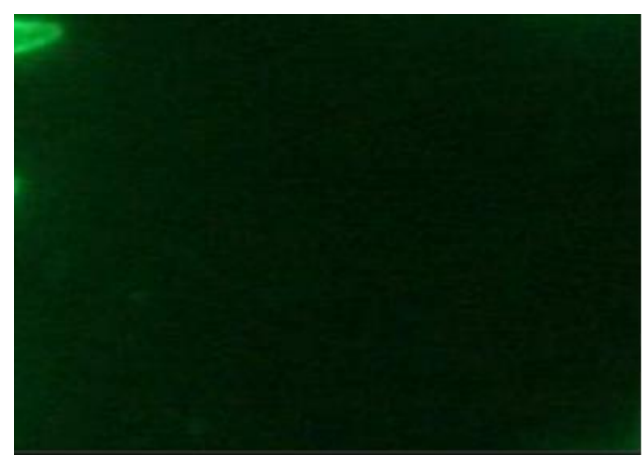

B

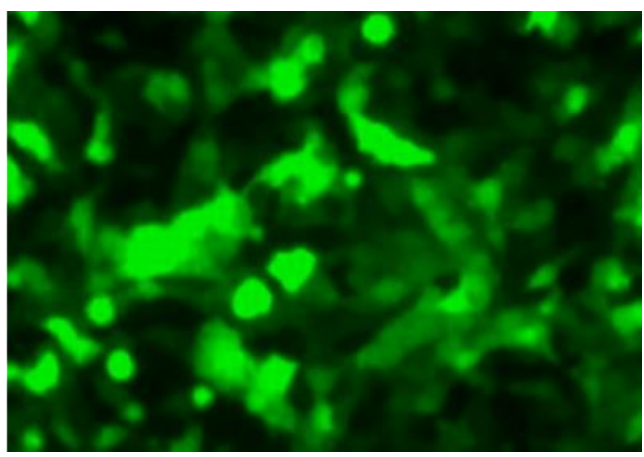

Fig. (2): $A=$ negative FAT (No fluorescent staining in the control non infected cells). $\mathrm{B}=$ positive FAT (Greenish fluorescence granules in the cytoplasm of infected cells indicated positive result).

The seven isolates were passaged for 10 times in each types of cell cultures (MDCK, Vero, BHK21 and MDBK cell culture), it was found that it produced the same shape of cytopathic effect (CPE) in all of them but with different time of appearance of $\mathrm{CPE}$ and virus titre. The $\mathrm{CPE}$ was characterized by rounding and swelling of the infected cells, then the affected cells had the appearance of irregular clusters of rounded highly refractile cells resembling bunches of grapes which after that detached from the culture surface (Fig.3). The same CPE was described by Bulut et al (2013), Yuanet al (2010).

It was found that as shown in table (2) that MDCK cells are the most suitable cell host for virus propagation yielding a highest virus titre of $\left(10^{7.5} \mathrm{TCID} 50 / \mathrm{ml}\right)$. MDBK cells were found to yield the lowest titre $\left(10^{4.8} \mathrm{TCID} 50 / \mathrm{ml}\right)$. These titres were obtained by the 7 th and 8 th passages. 
Kasem, S. G. et., al.
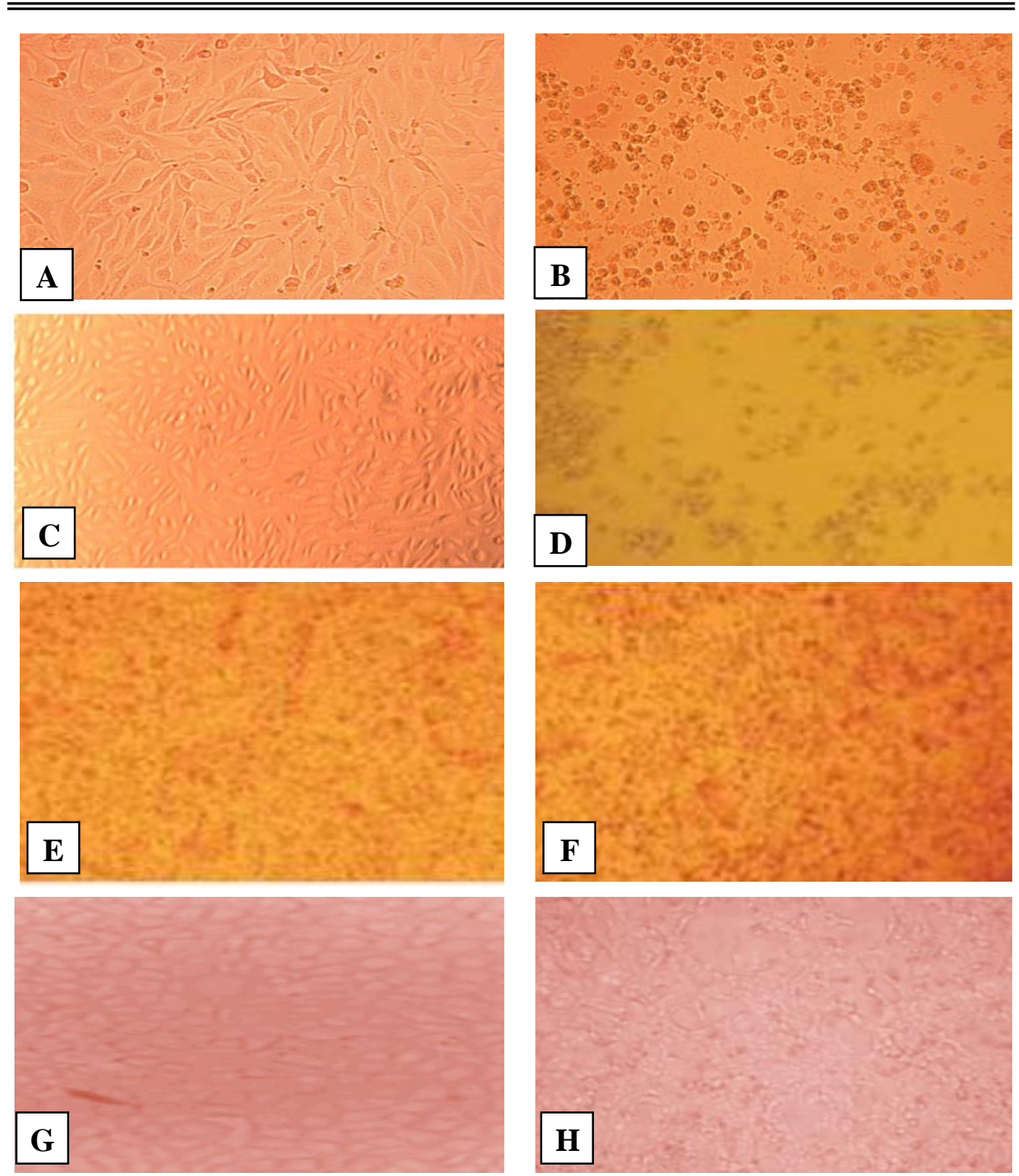

Fig. (3): Microscopical examination of cell cultures. $A=$ normal MDCK. $\mathrm{B}=$ infected MDCK with $\mathrm{CAV} . \mathrm{C}=$ normal Vero. $\mathrm{D}=$ infected Vero with CAV. $\mathrm{E}=$ normal BHK21. $\mathrm{F}=$ infected BHK21 with CAV. G= normal MDBK. $\mathrm{H}=$ infected MDBK with CAV.

$\overline{\text { Kafrelsheikh Vet. Med. J. Vol. } 13 \text { No. } 2 \text { (2015) }}$ 
Isolation And Identification Of Canine Adenovirus ...

Table (2): propagation of the isolated CAV-2 in different cell cultures

\begin{tabular}{|c|c|c|c|c|}
\hline \multirow{2}{*}{ Passage number } & \multicolumn{4}{|c|}{ Virus infectivity titre $(\log 10 \mathrm{TCID50} / \mathrm{ml})$} \\
\hline & MDCK & Vero & BHK21 & MDBK \\
\hline 1 & 3.5 & 2.9 & 2.4 & 1.5 \\
\hline 2 & 3.8 & 3.3 & 2.7 & 1.9 \\
\hline 3 & 5.0 & 4.5 & 3.9 & 2.2 \\
\hline 4 & 5.8 & 5.1 & 4.8 & 3.1 \\
\hline 5 & 6.2 & 5.7 & 5.2 & 3.5 \\
\hline 6 & 7.1 & 6.6 & 5.8 & 4.2 \\
\hline 7 & 7.5 & 7.0 & 6.1 & 4.6 \\
\hline 8 & 7.5 & 7.0 & 6.3 & 4.8 \\
\hline 9 & 7.5 & 7.0 & 6.3 & 4.8 \\
\hline 10 & 7.5 & 7.0 & 6.3 & 4.8 \\
\hline
\end{tabular}

\section{ACKNOWLEDGENET}

This research study was conducted and supported partially by Plant Pathology and Biotechnology Lab. (under ISO/17025 accreditation) and EPCRS Excellence Centre, Fac. of Agric., Kafrelsheikh University, Egypt. The other part of the research was conducted in Veterinary serum and vaccine research Institute. Abbassia, Cairo, Egypt. 


\section{REFERENCES}

- Appel M, Binn L.N. 1987. Canine infectious tracheobronchitis. Short review: kennel cough. In: Appel MJ (ed) Virus infections of carnivores. Elsevier Science Publisher, Amsterdam, pp 201-211.

- Appel M.J.G, Pickerill R.H, Menegus M, Percy D.H, Parsonson I.M, Sheffy B.E. 1970. Current status of canine respiratory disease. Procedings of the 20th Gaines Veterinary Symposium, Manhattan, USA, pp 15-23.

- Benetka V, Weissenbock H, Kudielka I, Pallan C, Rothmuller G, Mostl K. 2006. Canine adenovirus type 2 infection in four puppies with neurological signs. Vet Rec 158: 91-94.

- Bulut O, Yapici O, Avci O, Simsek A, Atli K, Dik I, Yavru S, Hasircioglu S, Kale M, and Mamak N. 2013. The Serological and Virological Investigation of Canine Adenovirus Infection on the Dogs. The Scientific World Journal Volume :, Article ID 587024, 6 pages .

- Buonavoglia C, Martella V. 2007. Canine respiratory viruses. Vet Res 38: 355-373. Canine Adenovirus Infection on the Dogs. Hindawi Publishing CorporationThe ScientificWorld Journal Volume:, Article ID 587024, 6 pages http://dx.doi.org/10.1155/:/587024.

- Chaturvedi U, Tiwari A.K, Ratta B, Ravindra P.V, Rajawat Y.S, Palia S.K, Rai A. 2008. Detection of canine adenoviral infections in urine and faeces by the polymerase chain reaction. J Virol Methods 149: 260-263. 
- Ditchfield J, Macpherson L.W, Zbitnew A. 1962. Association of a canine adenovirus (Toronto A 26/61) with an outbreak of laryngotracheitis ("kennel cough"). A preliminary report. Can Vet J 3: 238-247.

- Fairchild G.A, Cohen D. 1969. Serologic study of a canine adenovirus (Toronto A26/61) infection in dogs. Am J Vet Res 30: 923-928.

- Greene C.E. 2012. Laboratory diagnosis of viral and rickettsial infections and clinical epidemiology of infectious disease. In: Infectious diseases of the dog and cat, edited by C.E. Greene, St. Louis.. P. 1-9.

- Hamelin C, Jouvenne P, Assaf R. 1985. Association of a type-2 canine adenovirus with an outbreak of diarrhoeal disease among a large dog congregation. J Diarrhoeal Dis Res 3: 84-87.

- Hamelin C, Marsolais G, Assaf R. 1984. Interspecific differences between the DNA restriction profiles of canine adenoviruses. Experientia 40: 482.

- Hu R.L, Huang G, Qiu W, Zhong Z.H, Xia X.Z and Yin Z. 2001. Detection and differentiation of CAV-1 and CAV-2 by polymerase chain reaction. Veterinary Research Communications, 25:77-84.

- Koncicki A, Krasnodębska-Depta A, Mazur-Gonkowska B. 2006. New data concerning the significance of adenovirus in poultry pathogenicity. Med Weter 62: 739-743. 
- Lynch J.P 3rd, Fishbein M, Echavarria M. 2011. Adenovirus. Semin Respir Crit Care Med 32: 494-511.

- Macartney L, Cavanagh H.M, Spibey N. 1988. Isolation of canine adenovirus- 2 from the faeces of dogs with enteric disease and its unambiguous typing by restriction endonuclease mapping. Res Vet Sci 44: 9-14.

- Marusyk R.G. 1972. Comparison of the immunological properties of two canine adenoviruses. Can J Microbiol 18: 817-823.

- Marusyk R.G, Norrby E, Lundqvist U. 1970. Biophysical comparison of two canine adenoviruses. J Virol 5: 507-512.

- Parthiban M, Kumanan K, Kavitha Sunder, Senthil Kumar S. and Kathiresan D. 2009. Molecular detection of canine adenovirus using polymerase chain reaction and sequencing. Tamilnadu J. Veterinary \& Animal Sciences 5 (4) 140-142.

- Swango L.J, Eddy G.A, Binn L.N. 1969. Serologic comparisons of infectious canine hepatitis and Toronto A26/61 canine adenoviruses. Am J Vet Res 30: 1381-1387.

- Truszczyński M, Pejsak Z. 2012. Diarrheal diseases in pigs caused by facultatively pathogenic viruses. Med Weter 68: 9-14.

- Wieliczko A, Tomanek B, Kuczkowski M. 2003. Prevalence of infectious diseases in ring-necked pheasant flocks in Poland. Pol J Vet Sci 6: 177-182. 
- Wiśniewski E. 2004. Adenoviral infections in horse. Med Weter 60: 1139-1142.

- Yamamoto. 1966. Some physical and growth characteristics of a canine adenovirus isolated from dogs with laryngeotracheitis". Can.J.Microbiol., 12,303.

- Yamamoto R, Marusyk R.G. 1968. Morphological studies of a canine adenovirus. J. Gen. Virol. 2: 191-194.

- Yuan Z, Luo S, Xu H, Wang X, Li J, Yuan L, He L and Zhang X. 2010. Generation of E3-deleted canine adenovirus type 2 expressing the Gc glycoprotein of Seoul virus by gene insertion or deletion of related terminal region sequences. Journal of General Virology 91, 1764-1771. 